\title{
Spatial analysis of traffic accidents involving older adults in a city in the northeast of Brazil
}

Betise Mery Alencar Sousa Macau Furtado $0^{1,2}$ (D) Cristine Vieira do Bonfim ${ }^{3}$ ID Carmela Lilian Espósito de Alencar Fernandes' $\mathbb{1 D}$ Jacicleide Alves Oliveira² ${ }^{\text {ID }}$ Aline Galdino Soares da Silva ${ }^{4}$ ID

\section{Abstract}

Objective: to describe the epidemiological characteristics of traffic accidents involving older victims, responded to by the Mobile Emergency Service (or SAMU), and to analyze the spatial distribution of these events in the city of Olinda, Pernambuco, Brazil, from 2015 to 2018. Method: a composite cross-sectional study was performed, using SAMU service records as a data source. Descriptive statistics were applied, based on frequency distribution. For the mapping and detection of spatial clusters, the Kernel intensity estimator was used. Results: SAMU responded to 137 traffic accidents with older victims. The most affected age group were older adults aged 60 to 69 years $(81 ; 59.1 \%$ ), and there was a predominance of male victims $(90 ; 65.7 \%)$. The day of the week when most accidents occurred was Wednesday (29; 21.25\%), and the highest number of accidents occurred in the morning $(46 ; 33.6 \%)$. As for the nature of the accident, accidents involving pedestrians $(80 ; 58.4)$ predominated over collisions $(57 ; 41.6 \%)$. The Kernel intensity estimator identified a significant focus in the Peixinhos neighborhood, with other foci distributed throughout the coastal area. Conclusion: the study identified the characteristics of older victims of traffic accidents and areas of greatest risk for their occurrence in the city studied. This information can be useful when planning environmental engineering measures to be carried out in the regions identified, in order to reduce the frequency of accidents and injuries.
Keywords: Accidents, Traffic. Health of the Elderly. Prehospital Care. Emergency Medical Services. Spatial Analysis.

\footnotetext{
Universidade de Pernambuco, Faculdade de Odontologia, Programa de Pós-graduação Mestrado em Perícias Forenses, Recife, PE, Brasil.

2 Universidade de Pernambuco, Faculdade de Enfermagem, Recife, PE, Brasil.

Fundação Joaquim Nabuco, Diretoria de Pesquisas Sociais. Recife, PE, Brasil.

Secretaria de Saúde de Olinda, Coordenação de Geoprocessamento, Olinda, PE, Brasil.
}

The authors declare there are no conflicts of interest in relation to the present study.

No funding was received in relation to the present study. 


\section{INTRODUCTION}

The development of human societies has been accompanied by an increase in life expectancy and in the number of older adults. Between 2000 and 2050 , the proportion of the world's population aged over 60 years will double from around $11 \%$ to $22 \%$, with the number of people in this age group expected to increase from 605 million to two billion in the same period ${ }^{1}$. In Brazil, projections by the Brazilian Institute of Geography and Statistics (or IBGE) indicate that, in 2060, the percentage of the population aged 65 or over will reach $25.5 \%$ (58.2 million older adults). In 2018, this proportion was $9.2 \%(19.2 \text { million })^{2}$.

With population aging, there has been a corresponding increase in the total number of older users of roadways, either as vehicle occupants or as pedestrians ${ }^{3}$. A number of challenges associated with natural aging, including sensory, perceptual, cognitive and motor declines, can affect reaction time and the ability to drive $e^{4,5}$. Older adults are therefore a vulnerable group of road users, with high mortality and morbidity from traffic accidents ${ }^{3,6}$.

Geographic Information Systems (GIS) are commonly used to analyze traffic accidents ${ }^{7}$, allowing accident data to be presented visually, and the locations of such events to be analyzed ${ }^{8}$. By identifying the most common locations and/or sections of roads with high accident rates, traffic authorities can adopt preventive measures and apply regulations to reduce the frequency of accidents, deaths, injuries and financial losses ${ }^{7}$. The Kernel intensity estimation method, meanwhile, allows a simple assessment of data relating to the density of points or clusters of sites of accidents involving older adults ${ }^{9,10}$.

As traffic accidents represent one of the most important current public health problems, the analysis of the geographical distribution of such accidents involving the older population can help policy makers devise measures aimed at reducing them. The present study aimed to describe the epidemiological characteristics of events involving older victims of traffic accidents, responded to by the Mobile Emergency Service (or SAMU), and to analyze the spatial distribution of these events in the city of Olinda, Pernambuco, from 2015 to 2018.

\section{METHOD}

A cross-sectional study was carried out in the city of Olinda, Pernambuco, Brazil (Figure 1). The city has a territorial extension of $41,681 \mathrm{~km}^{2}$, with an estimated population of 389,494 inhabitants, distributed over 31 neighborhoods. Its demographic density rate is $9,360.236$ inhabitants $/ \mathrm{km}^{2}$, the highest in the state of Pernambuco and the fifth largest in Brazil ${ }^{2}$.

The study included SAMU responses to traffic accidents (collisions and being run over), the victims of which were 60 years of age or older, between January 1, 2015 and December 31, 2018. The data source was SAMU the response forms, which are filled out by the teams at the time of the call-out. These data were analyzed from September 2017 to January 2018. The variables analyzed were: demographic (sex and age group) and those related to the accident (type of accident, day of the week, time of occurrence and place of occurrence). The variables duration of call-out and type of vehicle involved in the accident were excluded due to the high non-completion rate: $25.5 \%$ and $35.8 \%$, respectively. Descriptive statistics were used for data analysis, using the $\mathrm{R}$ program (version 3.6.1).

For spatial analysis, the responses were categorized according to the neighborhood of occurrence and geocoded. The QGIS program, version 2.18, was used to map and detect spatial clusters with the Kernel intensity estimator. This is a non-parametric method used to identify spatial patterns, which calculates the density of events around each point, weighted by the distance from the point of each event ${ }^{11}$. Thus, peaks represent the presence of clusters or hot spots in the distribution of events, while low values represent events that occur less frequently in the area ${ }^{10,12}$. In the present study, a radius of 500 meters was adopted.

The project was approved by the Research Ethics Committee of the Complexo Hospital da Universidade de Pernambuco (the University of Pernambuco Hospital Complex), Hospital 
Universitário Oswaldo Cruz (HUOC) (the Oswaldo Cruz University Hospital), and the Pernambuco Cardiological Emergency Unit (or PROCAPE) under CAAE no 83723618.3.0000.5192.

\section{RESULTS}

During the study period, 137 SAMU responses to traffic accidents with older victims were recorded. Most of the victims were male $(90 ; 65.7 \%)$, while the average age was 70.4 years $( \pm 0.7)$, and ranged from 60 to 98 years. The highest frequency was for the group aged from 60 to 69 years $(81 ; 59.1 \%)$

Regarding the characteristics of the responses, the highest frequency was in the morning, from 6 am to $11: 59$ am $(46 ; 33.6 \%)$, followed by the afternoon, from 12 pm to 5:59 pm (44;32.1\%), on Wednesdays
(29; 21.25$)$ and Fridays $(28 ; 20.4 \%)$. The months of October $(20 ; 14.6 \%)$ and January $(18 ; 13.1 \%)$ had the highest number of call-outs. As to the nature of the accident, those involving pedestrians (80; 58.4) predominated over collisions $(57 ; 41.6 \%)$ (Table 1).

The spatial analysis, performed using the Kernel density estimator, showed that traffic accidents involving older adults responded to by SAMU in Olinda were concentrated in the neighborhoods of Peixinhos (the main focus), along Avenida Presidente Kennedy. Medium intensity areas were identified on the coast, located in the neighborhoods of Casa Caiada and Bairro Novo, intersected by the avenues Governador Carlos de Lima Cavalcanti and Getúlio Vargas, respectively, while there were less significant areas in the neighborhoods of Carmo, Varadouro, Fragoso, Bultrins and Salgadinho (Figure 2).

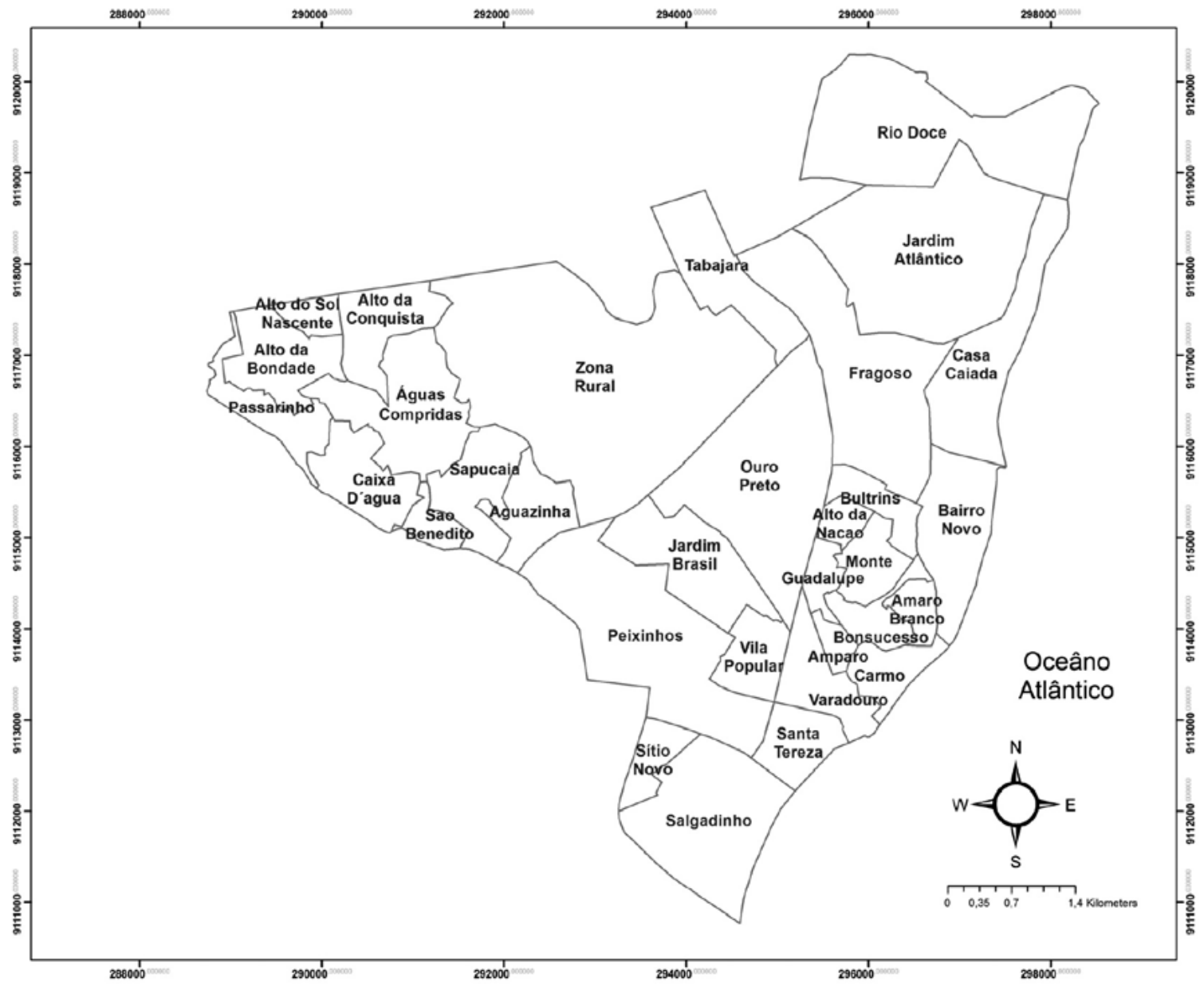

Figure 1. Location and divisions of neighborhoods in the city of Olinda, Pernambuco, Brazil. 
Table 1. Epidemiological characteristics of older victims of traffic accidents responded to by SAMU 192, between 2015 and 2018 in the city of Olinda, Pernambuco, Brazil, 2018.

\begin{tabular}{|c|c|}
\hline Variables & $\mathrm{n}(\%)$ \\
\hline \multicolumn{2}{|l|}{ Sex } \\
\hline Female & $47(34.3)$ \\
\hline Male & $90(65.7)$ \\
\hline \multicolumn{2}{|c|}{ Age group (in years) } \\
\hline 60 to 69 & 81(59.1) \\
\hline 70 to 79 & $35(25.5)$ \\
\hline 80 and over & $21(15.3)$ \\
\hline \multicolumn{2}{|c|}{ Time of occurrence } \\
\hline $00: 00$ to $05: 59$ & $7(5.1)$ \\
\hline $06: 00$ to $11: 59$ & $46(33.6)$ \\
\hline $12: 00$ to $17: 59$ & $44(32.1)$ \\
\hline $18: 00$ to $23: 59$ & $40(29.2)$ \\
\hline \multicolumn{2}{|c|}{ Day of the week } \\
\hline Sunday & 16(11.7) \\
\hline Monday & $16(11.7)$ \\
\hline Tuesday & $9(6.6)$ \\
\hline Wednesday & $29(21.2)$ \\
\hline Thursday & $20(14.6)$ \\
\hline Friday & $28(20.4)$ \\
\hline Saturday & 19(13.9) \\
\hline \multicolumn{2}{|l|}{ Month } \\
\hline January & 18(13.1) \\
\hline February & $10(7.3)$ \\
\hline March & $15(10.9)$ \\
\hline April & $7(5.1)$ \\
\hline May & $5(3.6)$ \\
\hline June & $10(7.3)$ \\
\hline July & $8(5.8)$ \\
\hline August & $10(7.3)$ \\
\hline September & $12(8.8)$ \\
\hline October & $20(14.6)$ \\
\hline November & $10(7.3)$ \\
\hline December & $12(8.8)$ \\
\hline \multicolumn{2}{|c|}{ Nature of the accident } \\
\hline Run over & $80(58.4)$ \\
\hline Collision & $57(41.6)$ \\
\hline
\end{tabular}

Source: Prepared by the authors based on data from SAMU. Olinda, Pernambuco. 


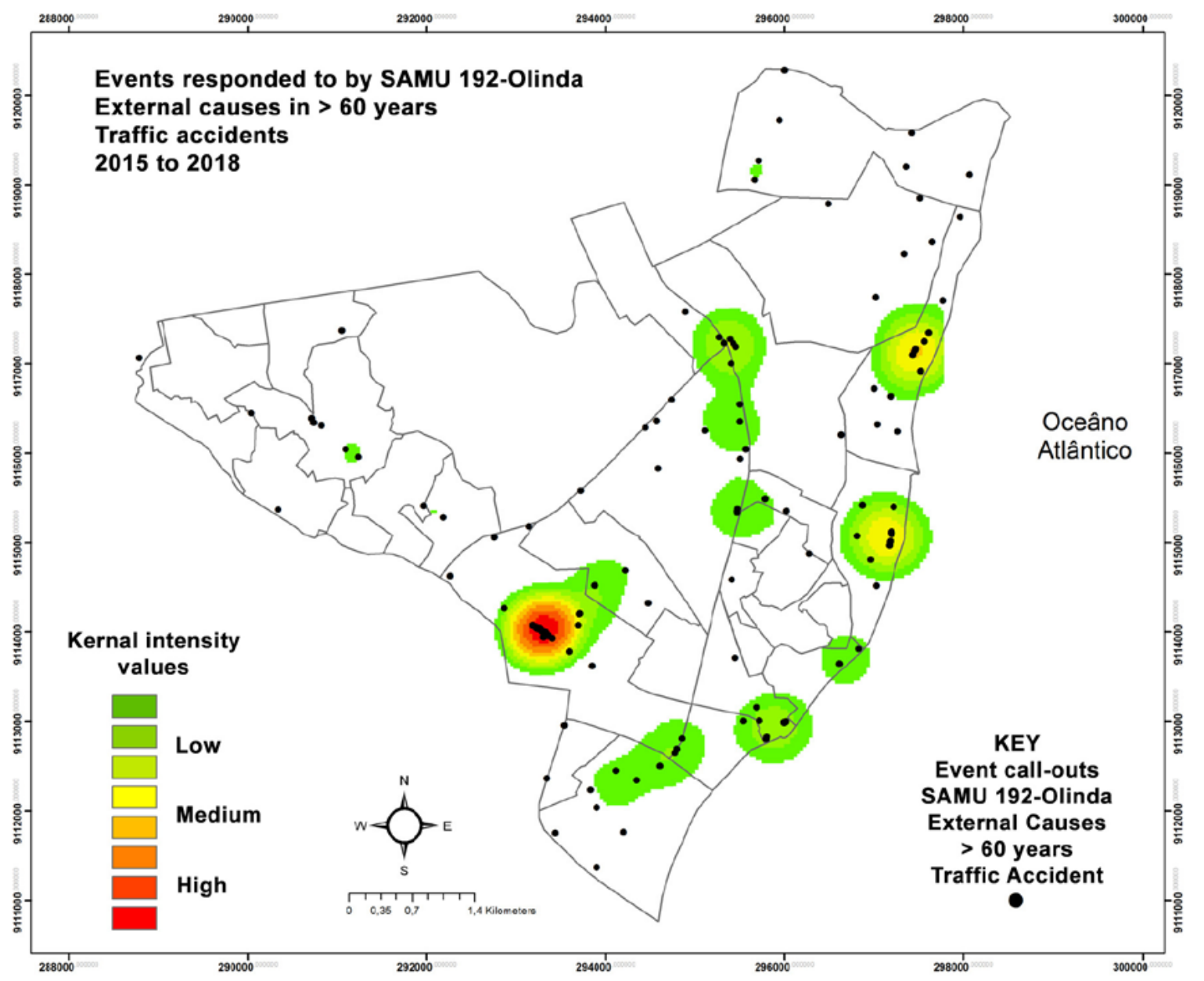

Figure 2. Spatial distribution and intensity of traffic accidents involving older adults responded to by SAMU from 2015 to 2018, Olinda, Pernambuco, Brazil.

\section{DISCUSSION}

Older adults account for a substantial number of hospitalizations and deaths caused by traffic accidents ${ }^{6}$. The present study investigated the demographic and occurrence profiles of pre-hospital emergency care in accidents involving older adults. Individual characteristics, such as sex, health conditions and socioeconomic status can provide a better understanding of individuals' vulnerability to old age, in combination with urban infrastructure and traffic conditions ${ }^{13}$.

The demographic characteristics of the present study demonstrated that the highest frequency of call- outs involved older adults, aged 60 to 69 years old. A recent review study on traffic accidents involving such older adults identified, as a demographic profile, the male sex and the age group from 60 to 69 years $^{14}$. The fact that younger older adults are the most affected shows is most likely because such adults have a more active life, with independence and autonomy, and activities outside the home form part of their daily routine ${ }^{15}$. A study ${ }^{16}$ that aimed to estimate the burden of traffic accidents and mortality among older adults found that the highest occurrence was in the 60 to 74 year old age group, among men, and involved mild trauma. In terms of mortality, older adults over 75 years old and pedestrians had a greater chance of death. 
In accidents of equal severity, the morbidity and mortality of older adults are higher than those of young adults ${ }^{17,18}$. A study in Chile identified greater vulnerability among older adults, with a 0.5 times higher rate of suffering a traffic accident, a 0.6 times higher rate of suffering an injury as a result of such accident, and a 1.3 times higher rate of mortality as a result of said accident, than young adults ${ }^{19}$. In Brazil, in 2017, the Mortality Information System recorded 6,030 deaths from traffic accidents among people aged over 60 years $^{20}$.

The occurrences mostly occurred during the day, during the week and in the months of January and October. A study that analyzed the risk of collisions according to age, sex and time of day showed that the risk of fatal injury remained constant throughout the day for drivers over 70 years old, reinforcing the greater frailty of this population to this type of accident ${ }^{21}$. Older adults experience a decline in driving skills and other body functions, increasing the likelihood of dying as a result of a traffic accident ${ }^{22}$. In Sweden, the spatial-temporal analysis of accidents involving older adults found that they occur on weekdays, during the day and in the coldest months of the year ${ }^{13}$. In a review of accidents involving older adults $^{14}$, it was observed that such adults use selfregulatory behaviors, that is, those involving the self-reported decision to protect oneself, with the adoption of strategies such as reducing exposure to traffic, driving at a reduced speed and avoiding driving at night.

Being knocked down was the main type of accident found. Literature highlights the significance of being run over as a result of traffic accidents involving older adults ${ }^{9,14,15}$. This can be explained by declining reflexes, a loss of hearing and vision, a loss of strength and agility, the presence of chronic diseases and the use of polypharmacy to treat comorbidities, which can negatively affect older adults when crossing public roads. Being run over is the main cause of morbidity and mortality from traffic accidents in this population group ${ }^{14,16,23}$.

When accidents were analyzed by the type of occurrence, it was observed that older pedestrians can be up to seven times more likely to die from traffic accidents than other age groups ${ }^{6,24}$, which can be explained both by the functional conditions of the older adults, by the traffic conditions in cities and, most of all, by poorly educated and reckless attitudes among drivers and motorcyclists ${ }^{14,22}$.

Improving services for pedestrians, urban traffic systems and hospital care are potential areas of intervention, especially in the health sector, with the aim of reducing the burden of traffic deaths among this population ${ }^{14-16}$. The need to establish comprehensive trauma management guidelines, adapted for and largely aimed at older adults, has been observed, considering the mortality rates among this population ${ }^{16}$.

Spatial analysis revealed that the areas with the highest concentration of accidents were those where most activities occur, and where the population is concentrated during the day. This seems to be a pattern of traffic accidents among older adults ${ }^{13,15}$.

The Kernel intensity map identified the Peixinhos neighborhood as a hot spot, in other words, an area with a greater number of accidents. This neighborhood has a dense commercial area, predominantly located on Avenida Presidente Kennedy, the main access road to the neighborhood, and is one of the main corridors in the city for buses and other vehicles, as well has having a poorly maintained road surface. The other hot spots, according to the Kernel density estimator, were Avenida Governador Carlos Lima and Avenida Getúlio Vargas, both of which have shops, banks, stores and a large flow of people, contributing to the occurrence of accidents, including those involving older adults. Inspections should be performed in these areas and preventive interventions carried out, including signaling for pedestrians and the installation of traffic lights with an audible warning and more time to cross, to allow the safe passage of older adults. Traffic education campaigns should also be promoted, and traffic speed reducers, improved lighting and pedestrian crossing layouts should be installed.

The implementation of preventive and corrective measures, based on studies using the Geographic Information System, provides spatial analysis through the surveillance of land transport accidents and allows the planning of preventive and protective measures for the affected populations in a timely 
manner ${ }^{9,25}$. In a spatial analysis study of deaths from traffic accidents in the micro-regions of the state of São Paulo, it is possible to identify the places with the highest mortality rates, allowing inspection actions to prevent accidents ${ }^{26}$.

Therefore, the potential of studies that use data georeferencing in urban centers can be seen, in order to identify the critical points for health promotion and accident prevention interventions.

The s study has certain limitations: a) the source of data used does not cover the totality of occurrences, and call-outs by the Fire Department are not included, nor victims rescued by third parties and referred to health services, or those who refused emergency care; b) the outcome relating to pre-hospital care could not be described due to the lack of communication between SAMU and hospital care, and so this information is not included in the database; c) in relation to secondary data, incompleteness and flaws in the completion of forms are inherent, and some variables could not be analyzed due to the high non-completion rate; and d) the limited number of observations made it impossible to carry out more robust statistical analyzes. Despite these limitations, the results of the present study confirm that a large number of accidents involving older adults occurred in certain areas of the city, which can assist in carrying out integrated preventive actions between the health sector and urban planning.

\section{CONCLUSION}

The present study showed that the age group with the highest frequency of accidents was younger older adults, with a predominance of men, and that most occurrences occurred on Wednesday, in the morning. Being knocked down was the main type of accident and the Kernel density estimator identified a highly expressive focus in the Peixinhos neighborhood, and other foci distributed throughout the coastal area. This is important information for health surveillance actions and for planning the emergency care network. Such information is also useful for urban planners, who may consider implementing environmental engineering measures in the regions identified to reduce the frequency of accidents and injuries.

Edited by: Ana Carolina Lima Cavaletti

\section{REFERENCES}

1. World Health Organization. Global strategy and action plan on ageing and health [Internet]. Geneva: WHO; 2017 [cited 2019 aug. 10]. Available from: https://www.who.int/ageing/WHO-GSAP-2017. pdf?ua=1

2. Brazilian Institute of Geography and Statistics. [Population projection 2018: number of inhabitants in the country must stop growing in 2047] [Internet]. Rio de Janeiro: IBGE; 2018 [cited 2019 aug. 10]. Available from: https://agenciadenoticias.ibge.gov.br/ agencia-sala-de-imprensa/2013-agencia-de-noticias/ releases/21837-projecao-da-populacao-2018-numerode-habitantes-do-pais-deve-parar-de-crescer-em-2047 [Português]

3. Etehad H, Yousefzadeh-Chabok Sh, DavoudiKiakalaye A, Dehnadi AM, Hemati H, MohtashamAmiri Z. Impact of road traffic accidents on the elderly. Arch Gerontol Geriatr. 2015;61(3):48993. DOI: $10.1016 /$ j.archger.2015.08.008

4. Boot WR, Stothart C, Charness N. Improving the safety of aging road users: a minireview. Gerontology. 2014;60(1):90-6. DOI: 10.1159/000354212

5. Fairfax LM, Hsee L, Civil I. An ageing trauma population: the Auckland experience. N Z Med J. 2015;128(1414):36-43.

6. Sadeghi-Bazargani H, Samadirad B, Moslemi F. A decade of road traffic fatalities among the elderly in north-west Iran. BMC Public Health. 2018;18(1):1-17. DOI: 10.1186/s12889-017-4976-2

7. Su JM, Wang YM, Chang CH, Wu PJ. Application of a geographic information system to analyze traffic accidents using nantou county, Taiwan, as an example. J Indian Soc Remote Sens. 2018;47(1):101-11. DOI: 10.1007/s12524-018-0874-z

8. Shafabakhsh GA, Famili A, Bahadori MS. GISbased spatial analysis of urban traffic accidents: case study in Mashhad, Iran. J Traffic Transp Eng. 2017;4(3):290-9. DOI: 10.1016/j.jtte.2017.05.005 
9. Santos AMR, Rodrigues RAP, Santos CB, Caminiti GB. Geographic distribution of deaths among elderly due to traffic accidents. Esc Anna Nery Rev Enferm. 2016;20(1):130-7. DOI: 10.5935/1414-8145.20160018

10. Kang Y, Cho N, Son S. Spatiotemporal characteristics of elderly population's traffic accidents in Seoul using space-time cube and space-time kernel density estimation. Plos ONE. 2018;13(5):e0196845 [17 p.]. DOI: 10.1371/journal.pone.0196845

11. Bailey TC, Gatrell AC. Interactive spatial data analysis. London: Harlow Essex; 1995.

12. Hashimoto S, Yoshiki S, Saeki R, Mimura Y, Ando R, Nanba S. Development and application of traffic accident density estimation models using kernel density estimation. J Traffic Transport Eng. 2016;3(3):262-70. DOI: 10.1016/j.jtte.2016.01.005.

13. Ceccato V. Patterns of traffic accidents among elderly pedestrians in Sweden review of european studies. 2018;10(3):117-33. DOI: 10.5539/res.v10n2p117

14. Furtado BMASM, Lima ACB, Ferreira RCG. Road traffic accidents involving elderly people: an integrative review. Rev Bras Geriatr Gerontol. 2019;22(3):e190053 [14 p.]. DOI: 10.1590/1981-22562019022.190053

15. Kerber VL, Santos NQ, Branco BHM, Bertolini SMMG,Bortolozzi F, Marques AP. Overrunning of elderly people on the streets: characterization and evolution, between 2007 and 2017, in a brazilian city. Saúde Pesqui. 2020;13(1):19-30. DOI: 10.17765/2176-9206.2020v13n1p19-30

16. Ang BH, Chen WS, Lee SWH. Global burden of road traffic accidents in older adults: a systematic review and meta-regression analysis. Arch Gerontol Geriatr. 2017;72:32-8. DOI: 10.1016/j.archger.2017.05.004

17. Lombardi DA, Horrey WJ, Courtney TK. Agerelated differences in fatal intersection crashes in the United States. Accid Anal Prev. 2017;99(Pt A):20-9. DOI: $10.1016 /$ j.aap.2016.10.030

18. Weijermars W, Bos N, Stipdonk HL. Serious road injuries in the Netherlands dissected. Traffic Inj Prev. 2016;17(1):73-9. DOI: 10.1080/15389588.2015.1042577
19. Bravo G, Duarte G, Cerda J, Castellucci H. Road traffic accidents of the elderly in Chile between the years 2008-2017: a register-based descriptive study. Medwave. 2020;20(5):e7923 [14 p.]. DOI: 10.5867/ medwave.2020.05.7923

20. Brazil. DATASUS [Internet]. Brasília, DF: Ministério da Saúde; 2019 - . Health Informations. Deaths due to external causes - Brazil, [cited 2019 aug. 10]. Available from: http://tabnet.datasus.gov.br/cgi/tabcgi.exe?sim/ cnv/ext10uf.def

21. Dorchin-Regev S, Rolison JJ, Moutari S. Crash risk by driver age, gender, and time of day using a new exposure methodology. J Safety Res. 2018;66:131-40. DOI: 10.1016/j.jsr.2018.07.002

22. Freitas MG, Bonolo PF, Moraes EN, Machado CJ. Elderly patients attended in emergency health services in Brazil : a study for victims of falls and traffic accidents. Ciênc Saúde Colet. 2015;20(3):701-12. DOI: 10.1590/1413-81232015203.19582014

23. Santos AMR, Rodrigues RAP, Diniz MA. Trauma by traffic accident In elderly people: risk factors and consequences. Texto \& Contexto Enferm. 2017;26(2):e4220015 [10 p.]. DOI:10.1590/0104-07072017004220015

24. Martin JL, Wu D. Pedestrian fatality and impact speed squared: cloglog modeling from french national data. Traffic Inj Prev. 2018;19(1):94-101. DOI: 10.1080/15389588.2017.1332408

25. Cabral APS, Souza WV, Lima MLC. Mobile Emergency care service: a survey of local land transportation accidents. Rev Bras Epidemiol. 2011;14(1):03-14. DOI: 10.1590/S1415790X2011000100001

26. Nunes MN, Nascimento LFC. Spatial analysis of deaths due to traffic accidents, before and after the Brazilian drinking and driving law, in microregions of the state of São Paulo, Brazil. Rev Assoc Med Bras. 2012;58(6):685-90. DOI: 10.1590/S010442302012000600013 